\title{
Conservation and Sustainable Development of Human-inhabited World Heritage Site: Case of World Heritage Lijiang Old Town
}

\author{
Yong Shao \\ College of Architecture and Urban Planning, Tongji University, Shanghai, China \\ Email:nyshao163@163.com
}

\begin{abstract}
Many studies on Lijiang Old Town, the World Heritage Site in China, criticise the negative impact that the rapid tourism development caused on its 'outstanding universal value'. However, tourism is a very important driving force for the local development of heritage sites in poverty areas of developing countries. So how to balance the relationship between 'heritage', 'community' and 'tourism' is an important issue for human-inhabited World Heritage Sites in developing countries. The paper takes Lijiang as a case, introducing the huge changes of the 'heritage' and 'community' with the rapid tourism development since it was inscribed on the World Heritage List in 1997. It points out that since 2002, according to the social and economic development status then, Lijiang has redefined its general goals to protect its authenticity and integrity as a World Heritage Site, to improve the living condition, to guarantee the interests of local people, and to enhance harmonious social development. A series of public policies have been designed and implemented to integrate heritage conservation with local development. Based on data analysis, field investigation and questionnaire survey, the paper analyses this intervention process and the experience and lessons of it, providing certain reference for the conservation and sustainable development of human-inhabited World Heritage Sites.
\end{abstract}

KEYWORDS human-inhabited World Heritage, heritage conservation, social development, tourism industry

Received April 15, 2017; accepted June 1, 2017.

\section{Introduction}

Surrounded by mountains, Lijiang Old Town is located in Lijiang-bazi (basin area) of Yunnan Province of China at an altitude of 2,400 m. On its north, the magnificent Yulong Mountain is covered with snow all the year round. Rivers, springs and ponds constitute a diverse water network here. Lijiang Old Town is made up of three parts: Dayan Old Town (including Heilong Pond), Baisha Housing Cluster and Shuhe Housing Cluster. Built up against mountains and near waters, they give a perfect glance into local cultures and ethnic customs. Features such as fluid urban space, dynamic water network, properly-sized residential architectures, comfortable spatial environment, and unique ethnic art reflect the creativity of human being in urban construction under given historical conditions and set up an excellent example of a livable environment in China (He 2011) (Figure 1).

In 1997, Lijiang Old Town was inscribed on the World
Heritage List on the basis of cultural criteria (ii), (iv) and (v). Since its inscription almost 20 years ago, the rapid growth of heritage tourism and related industries has brought serious contradictions and great impact on the heritage resources. However, tourism is a very important driving force for the development of World Heritage Sites in poverty-stricken areas in developing countries. How to balance the relationship between 'heritage', 'community', and 'tourism' is an important issue for human-inhabited World Heritage Sites in developing countries. So the paper takes Lijiang as a case, analysing the social, economic and heritage changes since it was inscribed on the World Heritage List in 1997, introducing the effort for achieving balance between 'heritage', 'community', and 'tourism' in the years of 2002-2005, and trying to explore effective paths for the conservation and local development of the living heritage. 



Figure 1 Bird's eye view of Lijiang Old Town. (Source: Zhang Tongsheng).

Figure 2 Location of Lijiang Municipality, Gucheng District and Dayan Old Town (Source: the author).

\section{Methodology}

The paper adopts the research methodology of comparative analysis, analysing the social, economic and heritage changes of Dayan Old Town (the main property area of Lijiang Old Town), Lijiang Municipality and Gucheng District where Dayan Old Town is located (Figure 2).

The paper also attempts to adopt interdisciplinary research methodology including economics, sociology, architecture, urban planning, etc., trying to comprehensively understand the huge changes in all aspects since Lijiang was included in the World Heritage List.

Based on the long-term tracking and research on conservation and development of Lijiang Old Town by the author's team from Tongji University, the analysis data which the paper adopts mainly include two sources: (1) the data published by the local government; (2) the large amount of first-hand data investigated in the scene separately in the year of 2002, 2005 and 2012 in the process of participating in the 'World Heritage Site-Lijiang Old Town Conservation Plan', including questionnaire survey, interviews, field surveying and mapping, etc. by the author's team.

\section{Economic Analysis of Lijiang Before and after Its Inscription on World Heritage List}

The inscription on the World Heritage List in 1997 was the biggest turning point in half a century for Lijiang Old Town. Since that time, tourism has brought unparalleled economic development opportunities to the people living in the heritage site and around, and Lijiang has grown from the little-known town in China's southwestern border area to the important and more developed city in the southwest, changing its backward and poor condition and becoming a world famous tourism city.

\section{Rapid Economy Development Caused by Tourism}

Resulting from the analysis of the economic date of Lijiang, the economic development from 1978 to 2011 can be divided into three phases:

The first phase is from 1978 to 1996. Before China's reform and opening-up, due to its remote location and traffic inconvenience, Lijiang region's industry and agriculture was very weak. It stayed for a long time in the traditional agricultural stage, some places even retaining the slash-and-burn habits. In 1978, the gross national product (GNP) of Lijiang was only 166 million CNY, and the agricultural output accounted for 53.3\% of GNP. On the whole, its social and economic development indicators showed an obvious gap compared with the average level of national and Yunnan Province. After 1990, the economic development of Lijiang speeded up, especially after 1994 when Lijiang decided to apply for World Heritage and adopted a tourism-oriented development strategy. In 1996, the GNP of Lijiang reached 2.086 billion CNY, tourists counted up to 1.106 million, and tourism income was 300 million CNY which accounted for only $14.3 \%$ of GNP (Figure 3, Figure 4).

The second phase starts in 1997 when the big event of the inscription of World Heritage List caused rapid tourism development of Lijiang, until 2003 when the development went into a brief trough due to the outbreak of the Severe Acute Respiratory Syndrome (SARS) in southern China between November 2002 and July 2003. In 2003, 


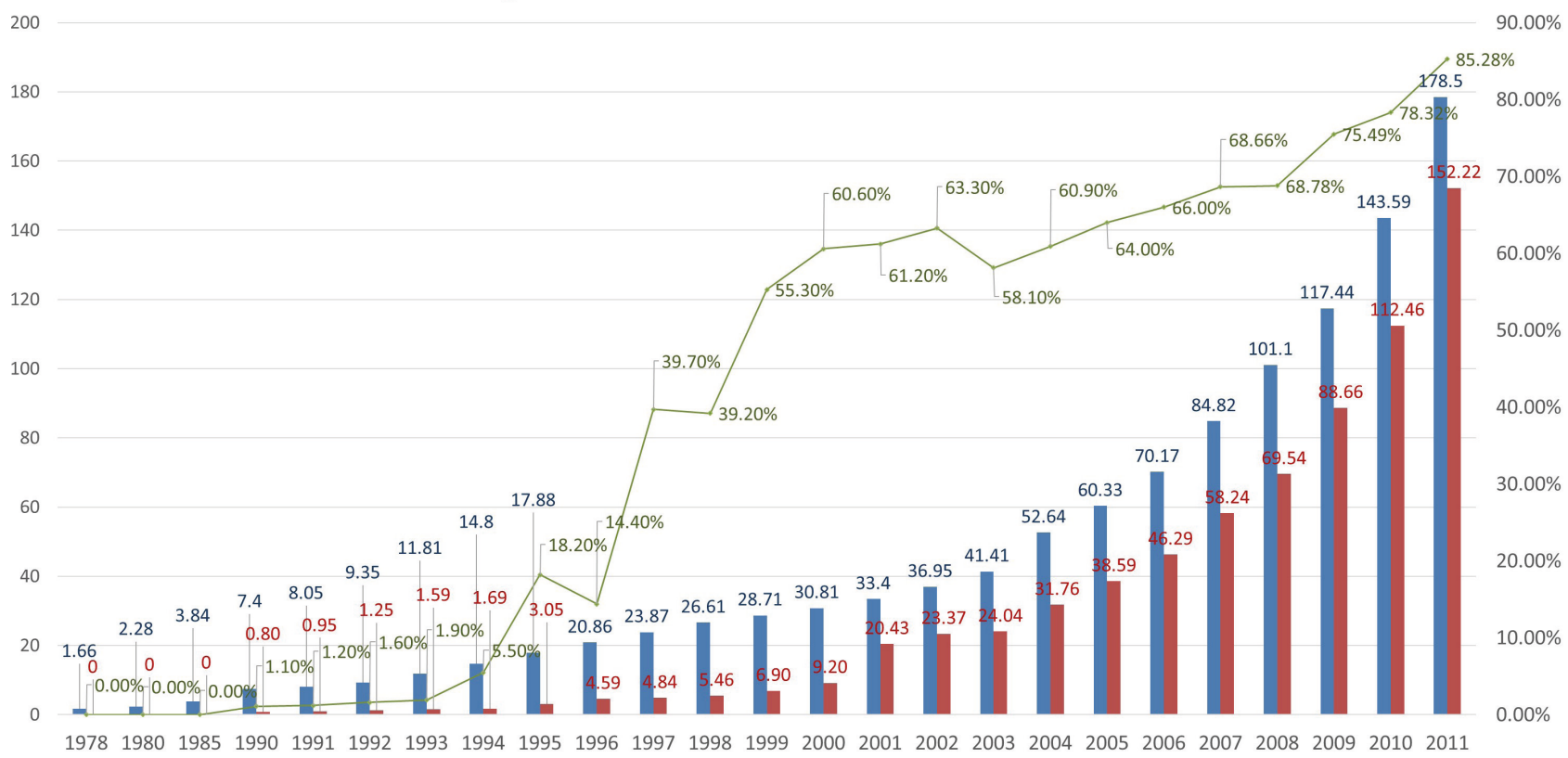

G GNP Income from tourism $\rightarrow$-Ratio of tourism income to GNP

Figure 3 The change trend of GNP and tourism income of Lijiang Municipality between 1978-2011 (Units: Billion CNY) (Source: Drawn by the author according to the Statistical Yearbooks and Statistical Bulletins of Lijiang Municipality and Gucheng District).

Numbers of tourists visit Lijiang and its old district from 1996 to 2011

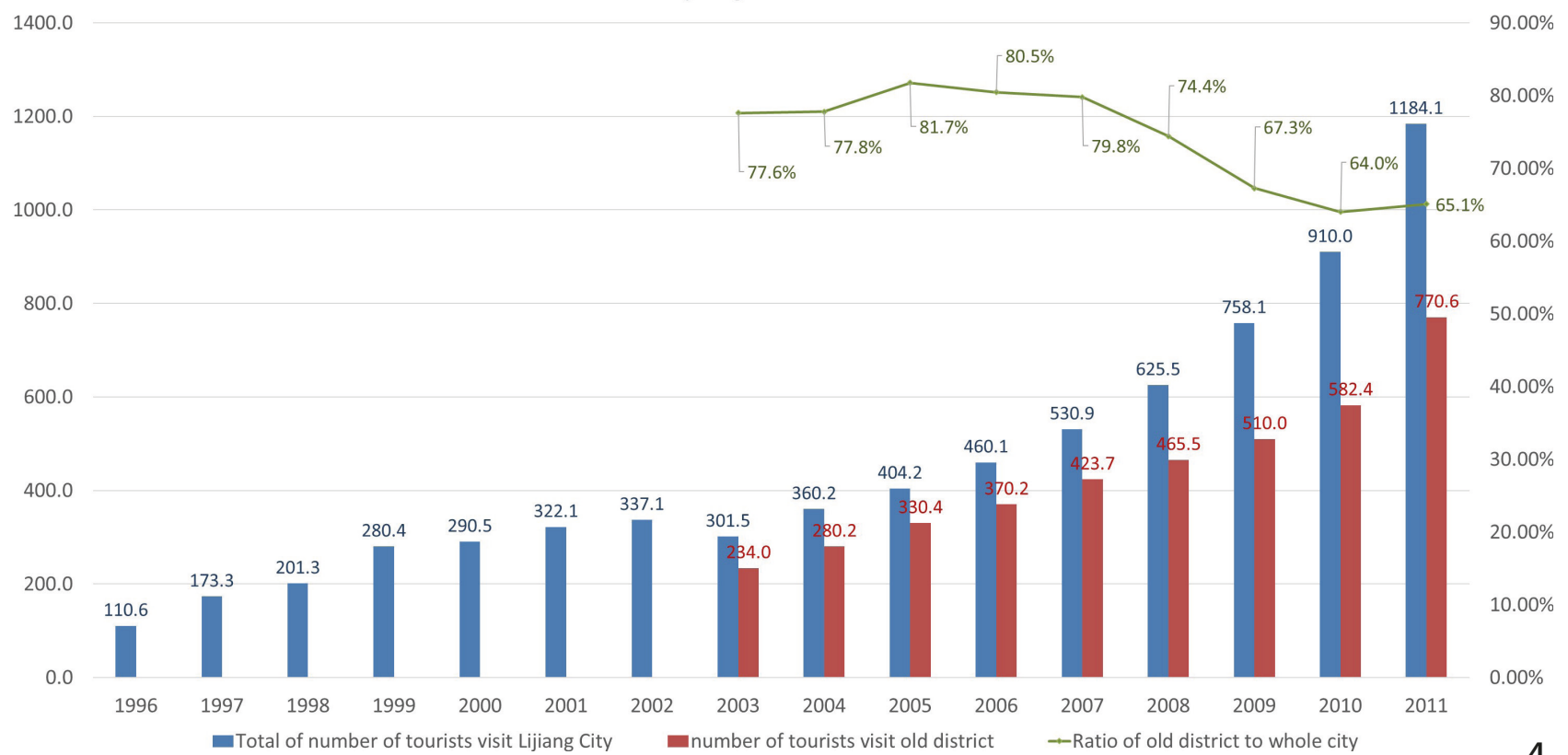

Figure 4 The evolution of tourist number of Lijiang Municipality and Gucheng District' between 1996-2011(Units: 10,000 persons) (Source: Drawn by the author according to the Statistical Yearbooks and Statistical Bulletins of Lijiang Municipality and Gucheng District).

tourists surpassed 3 million; tourism income reached 2.404 billion CNY, against a GNP of 4.141 billion CNY. The proportion of tourism income in the GNP continued to rise rapidly to $58.1 \%$, tourism became the most important pillar industry, and Lijiang got rid of its poor and backward situation (Figure 3, Figure 4).
The third phase dates from 2004 to 2011. In 2003, the administration division reform of Lijiang brought a new positive stimulus to its economic development. In 2007, the GNP reached 8.482 billion CNY, increased by $97.7 \%$ in five years and averagely increased by $14.6 \%$ every year, tourism contributing nearly $70 \%$. Since 2007 , the 
400

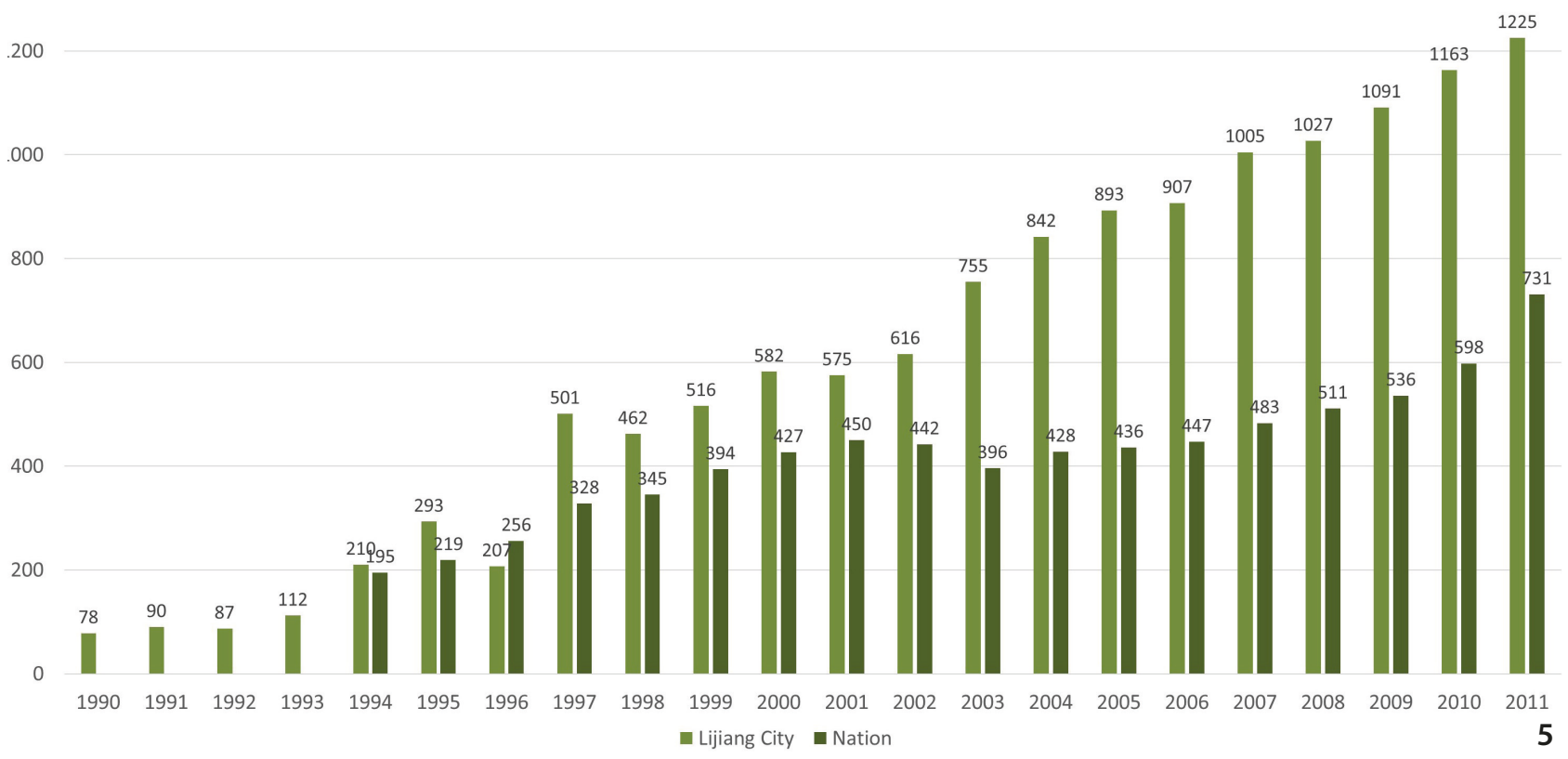

Figure 5 Comparative evolution of expenditure by tourists in Lijiang and in China, between 1990-2011 (Units: CNY per person per visit) ${ }^{2}$ (Source: Drawn by the author according to the Statistical Yearbooks and Statistical Bulletins of whole China, Lijiang Municipality and Gucheng District).

economic development accelerated again, with tourism taking on explosive growth, and the GNP in 2011 reached 17.95 billion CNY. From 2008 to 2011, average annual GNP growth rate was $21 \%$. The number of tourist arrivals during 2011 reached 11.8405 million, and tourism income reached 15.222 billion CNY, accounting for $85.2 \%$ of the GNP. It follows that tourism has played a decisive role in the economic development of Lijiang (Figure 3, Figure 4).

\section{The Main Features of the Tourism Development of Lijiang}

Firstly, the rapid development of Lijiang completely benefits from its rich, colourful and beautiful natural scenery and Lijiang Old Town which mainly comprised of Naxi minority, embodying the multi-ethnic harmonious development of China. The above data analysis clearly states that Lijiang Old Town is the main tourism destination of Lijiang since its inscription.

Secondly, the per capita consumption level of visitors of Lijiang is relatively high, driving the rapid development of the tourism economy. Through preliminary calculation, the per capita consumption of the domestic tourists of Lijiang increased from $78 \mathrm{CNY}$ in 1990 to $1,225 \mathrm{CNY}$ in 2011 which far exceeded that of the national level 731 CNY in 2011. It is concluded that the tourism consumption level is relatively high, which greatly promotes the local economic development (Figure 5).

\section{Local Residents Economic Benefits Brought by Tourism}

With the development of tourism and economy, the household income structure in the Dayan Old Town changed. Income sources diversified, covering commercial, tourism services, agriculture, retirement wage, migrant working incomes, etc., according to the survey in 2012 by the author's team.

Under the background of diversified income sources, the income improved distinctly in ten years according to the comparative analysis of data from the questionnaire in 2002 and 2012: While only $40 \%$ of households earned more than $20,000 \mathrm{CNY}$ in 2002, 48.6\% of them earned 20,000-50,000 CNY, 20.8\% earned 50,000-100,000 CNY, and $2.8 \%$ earned more than $100,000 \mathrm{CNY}$ in 2011.

We can see from the above analysis that tourism development is a very important policy for the poverty areas which can promote overall economic development rapidly and increase the income of residents in a relatively short period. That is the reason why government and local residents in the World Heritage Sites of developing countries always chose tourism as the main means of local development. 


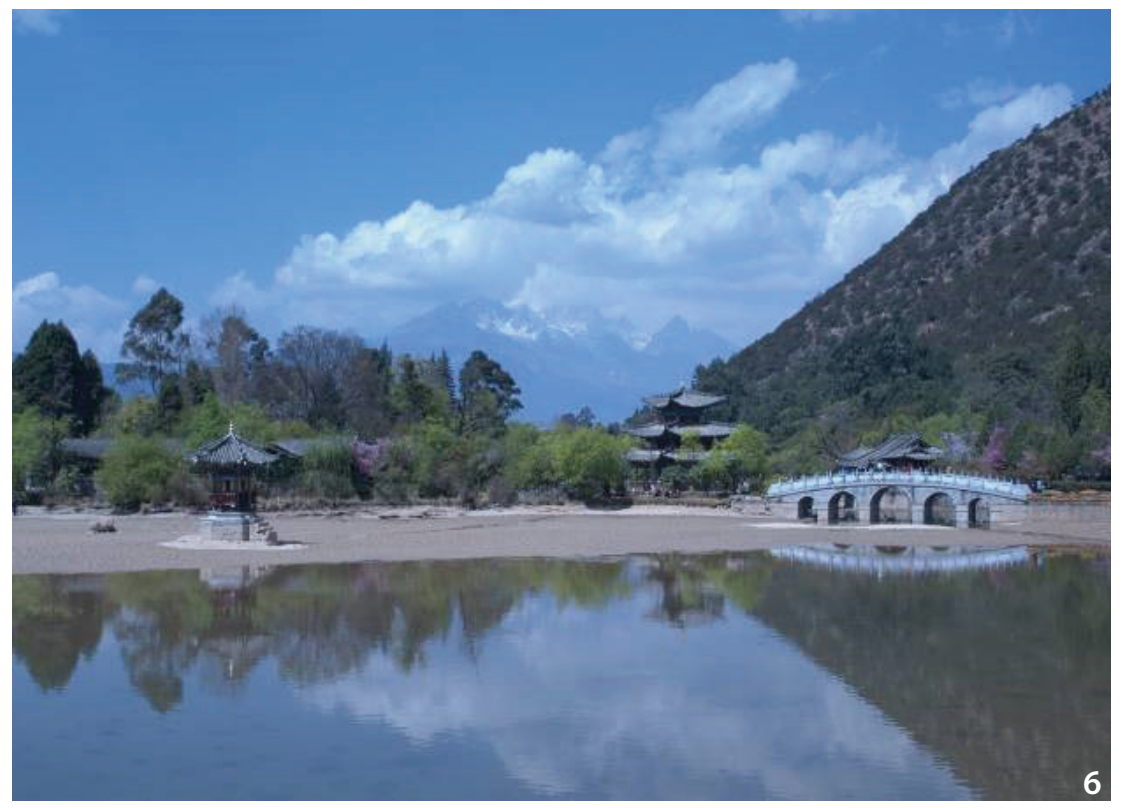

Figure 6 Heilong pool is almost dried up in 2012 (Source: the author).

\section{The Threat to the 'Outstanding Universal Value' Brought by Tourism to the World Heritage Site}

\section{The Constituent Elements of the Outstanding Universal Value of Lijiang Old Town}

According to the Statements on Outstanding Universal Value (OUV) of Lijiang in 2011, the elements that constitute its 'Outstanding Universal Value' include three complementary and inseparable aspects:

1. Natural environment. Including the natural elements that mainly consist of mountains, lakes and fields as well as the ecosystem they form.

2. Built environment. Settlements that take mountains as background, streets and rivers as framework, market squares as core, temples and pavilions as decorations, and traditional houses as basement.

3. Cultural environment. Including the social life, customs and habits, life interest, cultural traditions, arts and crafts, and national features of the residents of Naxi nation and other nations in Lijiang Old Town dating from hundreds of years.

But at present, Lijiang Old Town, which 'constitutes a harmonious living environment between human and nature, fully reflects the human wisdom to use the land' (Statements on OUV 2011), has faced a serious threat. Due to the rapid economic development, its natural, physical, and social and cultural environment have changed dramatically. On the one hand, this is caused by global climate change, the trend of globalisation, modernisation and urbanisation, while on the other hand the explosive tourism development still counts as a vital effect factor.

\section{The Vulnerability of the Surrounding Natural En- vironment of Lijiang Old Town}

The mountains and waters of Lijiang-bazi are the surrounding natural environment on which Lijiang Old Town relies for its existence. Yulong Snow Mountain is not only the sacred mountain in the local residents' hearts but also the source nurturing the old town residents and forming the particular landscape of the old town. But nowadays, the Snow Mountain is rapidly degrading: snow is decreasing sharply, with snowline rising at a speed of $15 \mathrm{~m}$ to $20 \mathrm{~m}$ in a year; and its glaciers are changing fast, retreating at a speed of $30 \mathrm{~m}$ in a year.

Heilong Pond and Yu River are the most important water resources of Dayan Old Town (including Heilong Pond). Drought has seriously affected the Heilong Pond in the recent years (Figure 6). In several field investigations in 2012, the continuous drought had dried up the pond in the Heilong Pond Park. According to the data by the groundwater level monitoring site in the South Gate Square of the old town, the level in some areas of the old town has currently declined by $19.1 \mathrm{~m}$ (Fan 2008).

In addition to global warming, the large number of tourism-related human activities also destroy the integral ecological environment of the upstream water. On the one hand, the construction of the ropeway on the Yulong Snow Mountain as well as the lakes excavation, golf course construction and urbanisation at the foot of the mountain have led to the hardening of piedmont buffer. On the other hand, the construction of all kinds of 

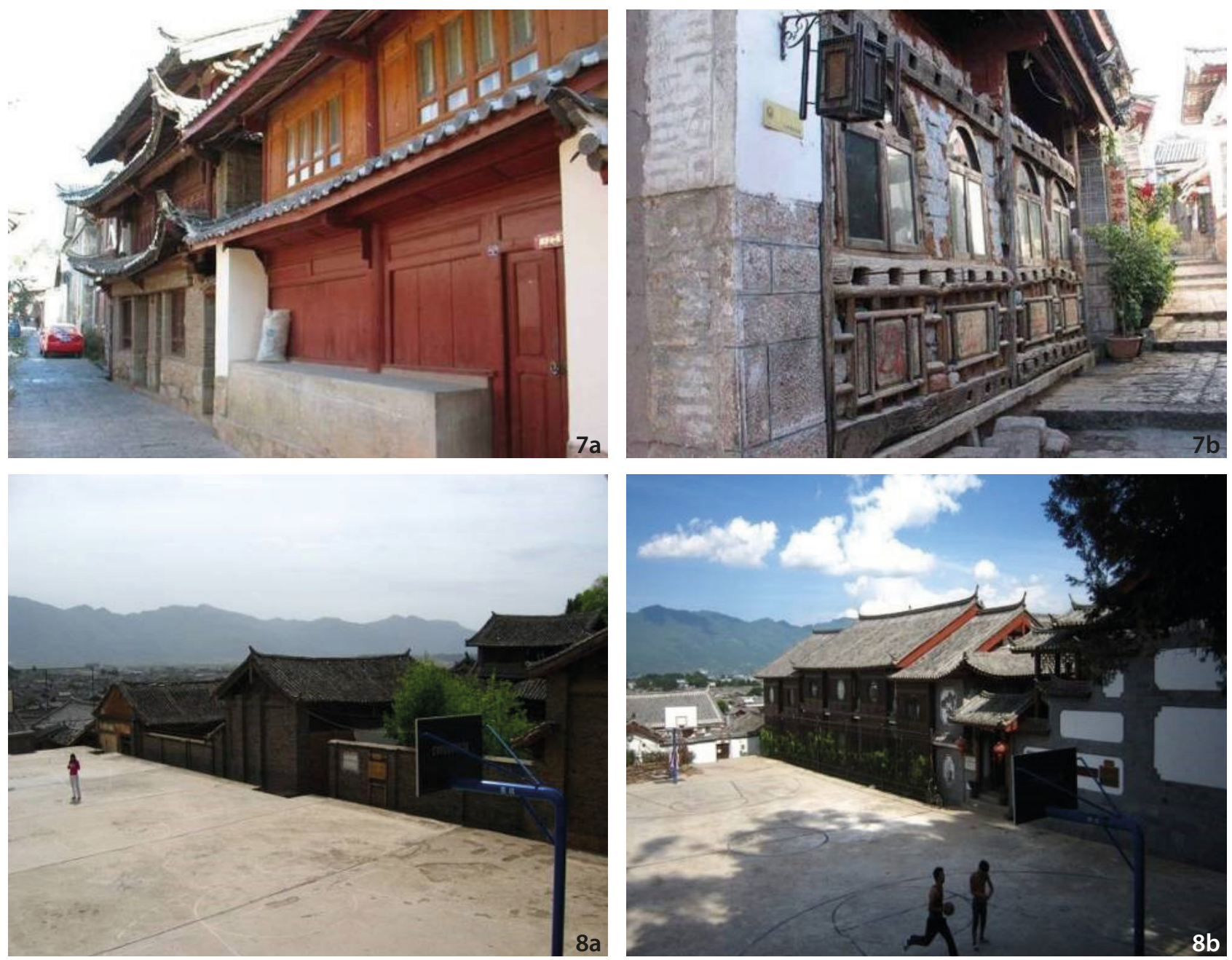

Figure 7a Traditional storefront (Source: the author).

Figure $7 \mathrm{~b}$ The modified storefront (Source: the author).

Figure 8a Resident courtyard before modification in 2007 (Source: the author).

Figure 8b Hotel after modification in 2012 (Source: the author).

entertainment facilities at the upstream of Yu River, the overgrowth of groundwater development, and the rapid growth of water consumption in the old town due to business development, have dried up the water body in the Heritage Site (Li 2004).

\section{Changes of Built Environment in Lijiang Old Town}

The pattern of Lijiang Old Town does not follow that of cities in Central China. During its long history, the city pattern was formed through the local living habits and cultural customs, and fully combined with topography. However, with the development of tourism, the built environment of the old town is also changing.

Firstly, farmlands adjacent to the old town soon become lands for stores and hotels for the tourism demand; meanwhile, the organic connection between Dayan Old
Town and the countryside scenery is being jeopardized by the increase of population in Lijiang.

Secondly, the development of tourism business causes frequent serious modifications of the street façades. Some modifications of the shop elevations along the street do not respect the authenticity principles, modifying the historical buildings with arbitrary ways and materials, producing a chaotic and fragmentary streetscape (Figure 7a, Figure 7b).

Thirdly, with the development of tourist accommodation industry, plenty of traditional dwellings are being transformed into folk inns. Among them there are some good modification cases following the traditional architectural style, as well as some bad ones pursuing to maximize room number and size, rather than the conservation of the traditional authentic features of the courtyards, so that the the number of traditional courtyard houses is 

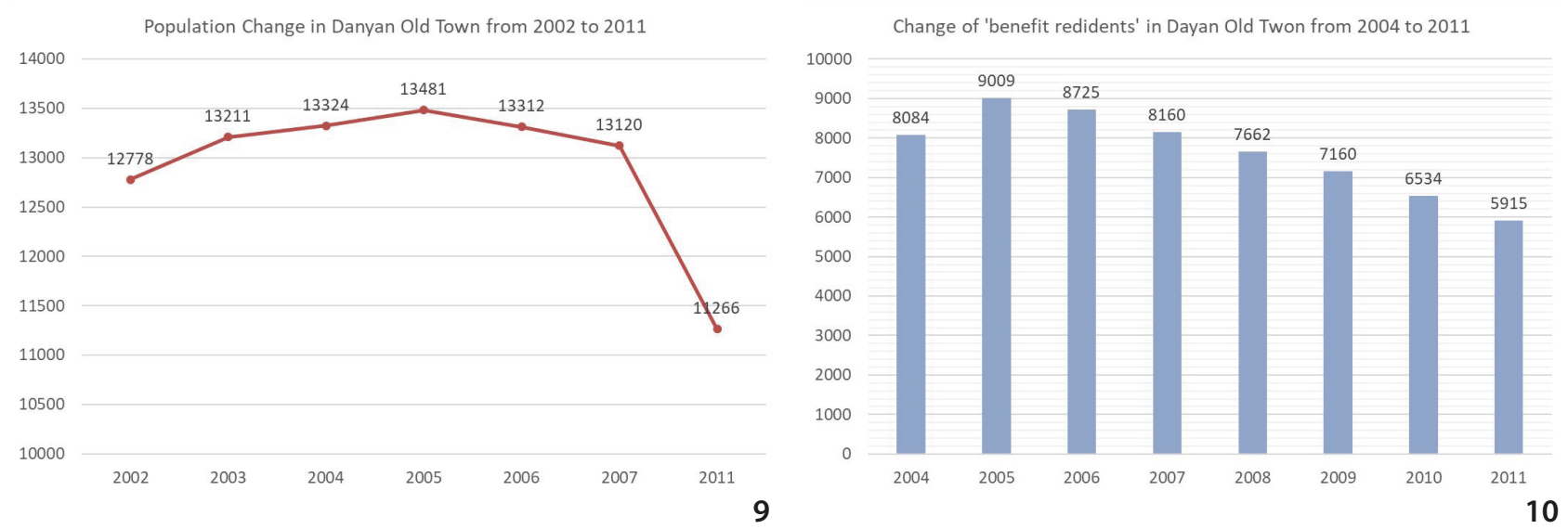

Figure 9 Evolution of the total population of Dayan Old Town, between 2003-2011 (Units: person) (Source: Drawn by the author according to the Statistical Yearbooks and Statistical Bulletins of Lijiang Municipality and Gucheng District). Figure 10 The population of 'benefited residents' of Dayan Old Town from 2004 to 2007 (Units: person) (Source: Drawn by the author according to the Statistical Yearbooks and Statistical Bulletins of Lijiang Municipality and Gucheng District).

facing the threat of gradual reduction in Lijiang Old Town (Figure 8a, Figure 8b).

\section{The Social and Cultural Environment Changes}

\section{Change of Social Structure}

The rapid development of tourism in Lijiang Old Town has affected the town's functions and has brought great impact on the local life. There are mainly three issues found from statistics as follows:

1. The ratio of indigenous people moving out of the property area is relatively high.

Although the old town's population mainly consists of Naxi ethnic group, the place becomes less attractive to indigenous people. There are two reasons. On the one hand, private owners cannot afford to restore the obsolete infrastructure; on the other hand, the demand for rented accommodation is growing as a large number of migrant merchants swarm into the old town. Therefore, indigenous people, out of convenience and economic considerations, gradually move out of the town. Their disappearance has finally led to serious damage of the authenticity of Lijiang, where the indigenous people's living space composes the main body of heritage.

According to the statistical yearbooks of Lijiang $\mathrm{Mu}$ nicipality and Gucheng District, while the registered population $^{3}$ of Dayan Old Town still gradually increased from the year of 2002 to 2005, it gradually decreased since 2005, from 13,481 in 2005 to 11,266 in 2011 , reducing by $16.4 \%$ (Figure 9).

The change of 'benefited residents' ${ }^{4}$ reflects the change of the indigenous people actually living in the property area. While in 2004 there were 2,176 households $(8,084$ persons) receiving subsidy, in 2011 the number decreased to only 1,576 households (5,915 persons). From 2004 to 2011 , the households reduced by $27.6 \%$ and the population reduced by $26.8 \%$. In seven years there were nearly one-third of the indigenous people leaving the old town, and the ratio of moving out was increasing, from $3.15 \%$ in 2006 to $9.47 \%$ in 2011 (Figure 10 ).

2. 'Hollow' phenomenon arose in the core of property area with the moving out of indigenous people.

According to the analysis of the distribution of 'benefited residents', the ratio of moving out in Xinhua, Xinyi community during the seven years from 2005 to 2011, reached separately $72.5 \%$ and $50.2 \%$, which are the most core communities of Dayan Old Town.

Take Xinhua community for example, while there were 262 households (930 persons) of 'benefited residents' in 2005, in 2011 there were only 74 households (256 people). In the neighbourhood around Sifang Street where businesses were most intensive, there were only six households (14 people) of residents actually living there (Figure 11). 3. An increasingly serious unstable social structure in the property area.

On the one hand, young people are among the first to leave the old town to pursue modern life and economic interests, which accelerates the ageing of the population left within the town. According to a social survey in 2002 by the author's team, people over 60 years old accounted for more than $35 \%$ of the total population.

On the other hand, the large number of migrants renting houses in the town is the main cause of unstable social structure. According to the Statistical Bulletin of Gucheng District in 2005, the 'benefited residents' population of 


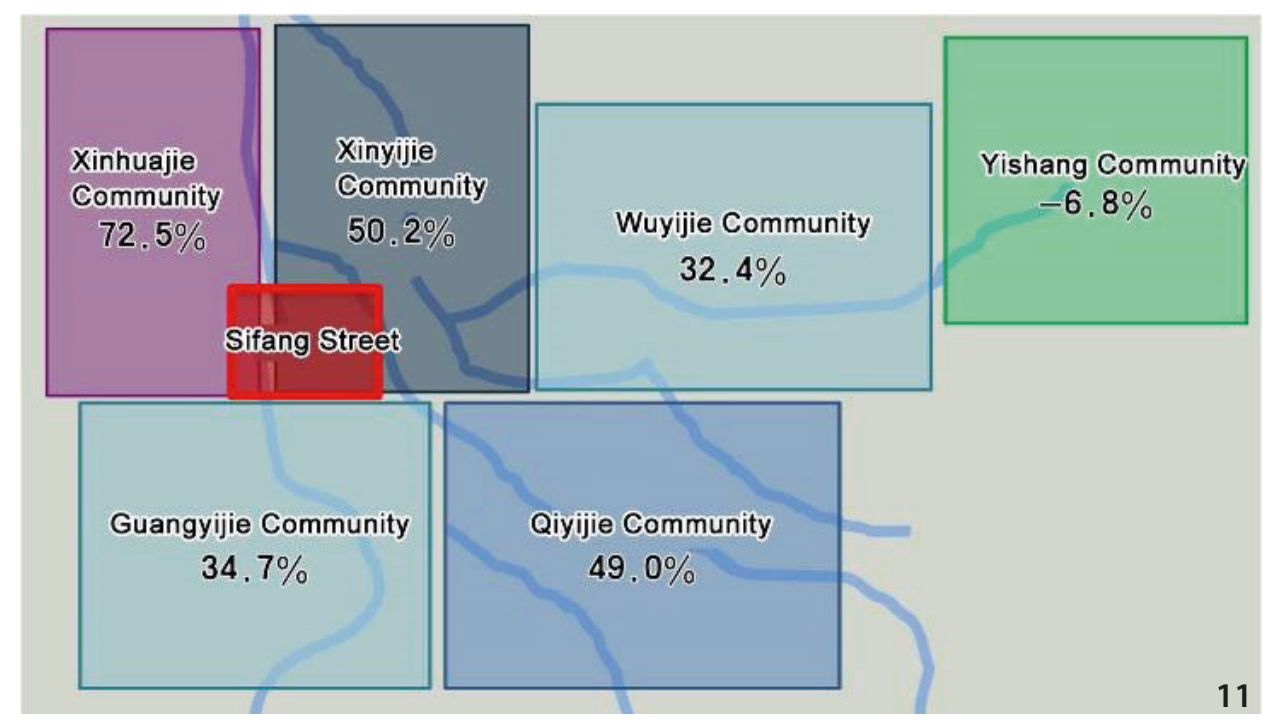

Figure 11 Ratio of indigenous people moving out of each community in Dayan Old Town, between 20052011 (Source: Drawn by the author according to the statistical yearbooks and statistical bulletins of Lijiang Municipality and Gucheng

1 District, and the social survey).

the main six communities in Dayan Old Town was 8,804 , and the migrant population ${ }^{5}$ was 9,502 . While in 2011, the 'benefited residents' population remained only 5,915 , and the migrant population reached 12,200 , with a rate of 1:2.06. The inversion between local residents and the migrant population was becoming more and more serious. 4. The Crisis of the Transmission of Intangible Heritage

Lijiang is facing a crisis in the transmission of intangible culture, much as in the rest of China. The most severe problem is the ageing of most inheritors of traditional knowledge, together with the lack of young generation learners.

Tourism development has provided a good opportunity for the inheritance of intangible culture. The performance of Dongba music, the Dongba ancient books' inscription on 'World Memory Heritage' in 2003, and the traditional handicrafts have been explored as tourism products.

However, in 1999 there were more than 80 Dongba inheritors in Lijiang, while the number of Dongba inheritors declined sharply during the next several years and remaining few now. According to the age statistics of 59 inheritors of intangible culture, only two persons are under the age of 40 , accounting for $4.4 \%$, and only $44.4 \%$ of inheritors are between the ages of 40-60, while most of the inheritors are older, six persons of whom have died (Yang 2010).

According to a social investigation made by the author's team, young people now seem reluctant to learn knowledge and skills such as folk art skills, singing and dancing, and Dongba texts, which bear strong local ethnic characters but take a lot of time and efforts. Even some inheritors themselves prefer their children to earn money through engaging in the profitable tourism industry, rather than learn the handicraft. The value of intangible heritage is changing due to the commercialisation and industrialisation caused by the tourism development.

\section{Analysis on the Public Policies on Heritage Conservation and Development of Lijiang Old Town after Its Inscription as a World Heritage Site}

From above data analysis, the year of 2005 was an important turning point for heritage conservation and development of Lijiang Old Town since its inscription: before 2005 the heritage conservation of the old town was gradually improved by restricting disorderly development, as the tourism industry was relatively weak; from 2003, a series of 'policies for benefiting residents' were established to retain stable indigenous population. However, after 2005 , although the ratio of the tourist number and tourism income of Gucheng District decreased from $86.8 \%$ and $81.7 \%$ of Lijiang Municipality to $62.8 \%$ and $65.1 \%$ in 2011 because of the whole regional tourism strategy, the total number of tourists in Dayan Old Town was dramatically increased (Figure 4). On the other hand, the 'policies for benefiting residents' were not adjusted adaptively according to the new tourism trend, so the efficiency of the policies became more and weaker.

The analysis of the process will be conducive to understand the experience and lesson of public policies on tourism development of poverty areas of developing countries.

\section{General Objectives of Conservation and Devel- opment of Lijiang Old Town}

In 2002, based on the conservation, social and economic 

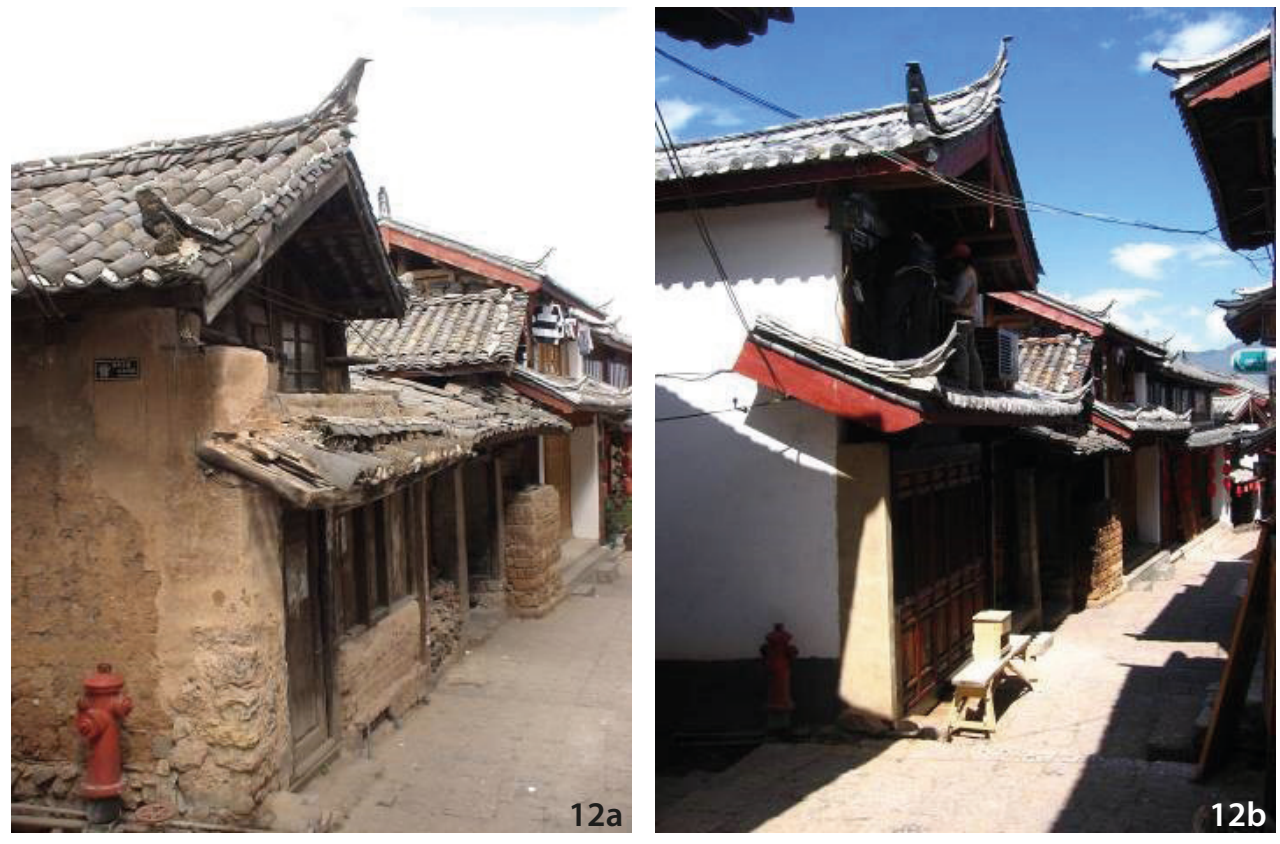

Figure 12a and $12 \mathrm{~b}$ Comparison of residential houses before and after restoration (Source: the author). development status of Lijiang, dual objectives have been redefined by Tongji University and the the Conservation Commission Office of the World Heritage Site-The O1d Town of Lijiang ${ }^{6}$ while developing the 'Conservation Planning of World Cultural Heritage Site-The Old Town of Lijiang':

1. To guarantee the authenticity and integrity of World Heritage.

For a living World Heritage, we stress integrated conservation rather than considering it as a single monument. The scope of efforts includes protecting spatial layout, protecting the skyline, inheriting traditional culture and developing the traditional economy, as well as maintaining the indigenous people and improving their lives and work environment. Traditional residential houses of Lijiang are not only the heritage itself but also the ethnic architectural style that perfectly combines nature with craft, art and functions, boasting great intangible and tangible cultural heritage.

2. To improve living conditions, protect the interests of the indigenous people.

The inscription of Lijiang has brought about the rapid growth of tourism, which causes threats to the interests of the indigenous people and their social fabric. In order to address the threats, a long-term and cyclic 'Subsidy Plan for Restoration of Indigenous People's Houses' is developed between public and private sectors. On the one hand, it improves living conditions through public fund as well as an eligible private fund of indigenous people; on the other hand, through subsidy agreement and the establishment of new community centres, it makes indigenous people willing to live and work in the old town. Sufficient job opportunities are provided to them, and harmonious social development is thus realised.

Therefore, it is necessary to integrate heritage conservation with community development and formulate the following public policies.

\section{Public Policies on Heritage Conservation and Community Development of Lijiang Old Town.}

The Subsidy Plan for Restoration of Indigenous People's Houses

From the perspective of guaranteeing the world heritage's authenticity and ensuring harmonious social development, the CCO signed the 'Agreement on Restoring Traditional Residential Houses in Lijiang Old Town' with the Global Heritage Fund (GHF) in 2002. In order to attain desired objectives, following requirements must be met while applying for and using the fund:

- Owners of houses should be local residents who have lived in the old town for more than 10 years. Heirs should be deemed as equal;

- Houses for which subsidies are claimed should be nonprofit and will be so after restoration;

- Annual household income should be less than 20,000 CNY (the number varies yearly according to the economic growth rate of last year);

- Restoration should be implemented in accordance with the 'Restoration and Maintenance Guidelines for Traditional Residential Houses in Lijiang Old Town'. The amount of subsidies for restoration projects 


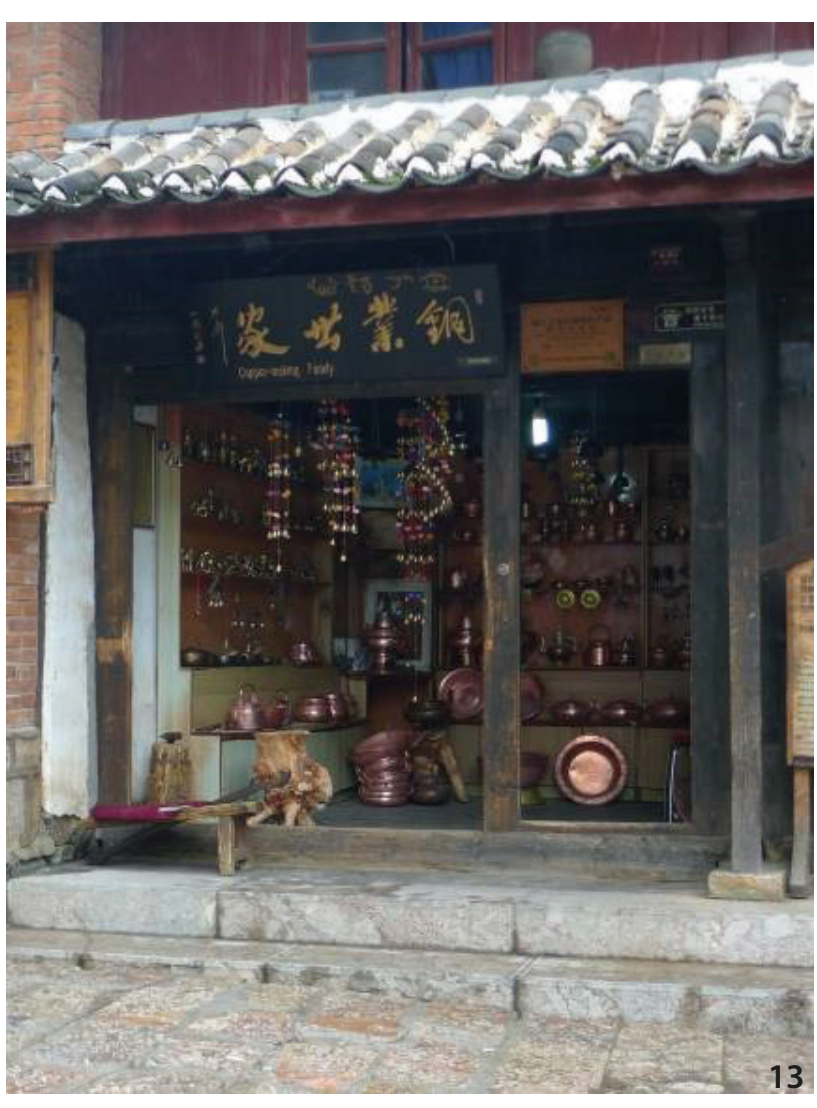

Figure 13 'Cooper Family' is one of the traditional handcraft shops supported by Business Permit programme (Source: the author).

approved is determined by factors such as the houses' historical value, the degree of damage, fund needed for restoration and household income. The shortfall, if any, is to be solved by the residents.

From 2002 to 2005, the traditional residential houses have been restored in Lijiang Old Town, with an area of $41,760 \mathrm{~m}^{2}$. The total restoration cast amounts to 444,000 USD, and the average per household stands at 2,550 USD. Of the total cost, $50 \%$ is provided by the fund set up by Lijiang Municipal Government and GHF, and residents pay the other $50 \%$. For poverty-stricken families, the proportion of subsidy would be raised (Figure 12a, Figure 12b).

\section{Job Opportunity Program for Indigenous People}

1. Creation of the Service Centre to develop a self-service social system.

In 2004, a Service Centre was set up and supported financially by Lijiang Old Town Management Co., Ltd. Upholding the spirit of 'self-sufficiency and self-development', its major functions include providing manpower transport for regular residents of the old town, cleaning public areas, etc.

The Service Centre not only generates a large number of job opportunities but also transports daily goods for free, which reduces the living cost of residents. Thus the transportation, security and environment of the old town have been greatly improved.

2. Establishment of Business Permit mechanism to protect the job opportunities of indigenous people.

The Business Permit mechanism initiated in Lijiang old Town from 2003 is the first business access mechanism for urban heritage in China. The location and the content of shops has been defined to ensure conservation of the physical space of the site. Apart from that, it also stipulates: for a business with five or more employees, more than $70 \%$ of them should be local residents; for a business whose employees are less than five, at least one of them should be a local resident.

Indigenous people have been encouraged to open handcraft shops, such as the He Zhigang Academy and Copper Hammering Mill, providing both a place to learn local culture and opportunities for visitors to acquire an in-depth understanding of the local culture of Lijiang (Figure 13).

\section{Evaluation of the Conservation and Develop- ment Policy}

From the objectives and implementation of Lijiang old Town's heritage conservation and social development policies, the following conclusions could be drawn, which are highly instructive and helpful for the conservation and development of other similar heritage sites.

1. To integrate social development into heritage conservation is a hard but necessary job.

Though most traditional residential houses in the 'Subsidy Plan' do not bear outstanding historical, cultural and architectural value, they make up the main body of Lijiang Old Town and fully exhibit the wisdom of ethnic architecture. They are the place where minority groups such as Naxi and Bai live. The life and the distinctive culture of indigenous people are closely tied up with the physical environment of the old town. Therefore, the restoration of traditional residential houses composes a basic part in the conservation of Lijiang Old Town. A long-term, cyclic restoration plan has been adopted, and a certain number of houses have been restored and maintained annually according to the 'Restoration and Maintenance Guidelines for Traditional Residential Houses in Lijiang old Town', ensuring sufficient protection and rational utilisation of wooden architectures in the old town.

This well planned, and public-private cooperative restoration plan for traditional residential houses, with 
its professional guidance and supervision, won the 2007 Award of Merit for Cultural Heritage Conservation of UNESCO Asia-Pacific region.

2. Properly guiding public and private funds is the key to effective policies.

Heritage conservation in China has always been restricted by the shortage of funds. Objectively analysing the problems at heritage sites, we can find the existence of a large amount of private fund, and its investment trend within the sites has not received enough attention. That is to say, if not properly guided, this amount of fund is likely to be a destructive force. Whereas, if properly guided, it would be a driving force for conservation.

Aiming at the public interests of heritage conservation and social development, the 'Subsidy Plan' integrates the fund from government and GHF with the private fund of indigenous people, offering the willingness to conserve and restore traditional residential houses, the most valuable heritage main body of Lijiang Old Town.

3. Participation of the government, communities, experts and civil force is the guarantee far effective implementation of policies.

Since 2002, all walks of life in Lijiang Old Town have participated in the implementation of policies. First, a working group has been set up and properly staffed by the CCO which is in charge of project implementation. Then, as the major coordinator of the project, neighbourhood committees of the old town, with the help of experts from Tongji University and Yunnan University of Science and Technology, explain the objectives and plans of restoration to every household, handle restoration applications and discuss restoration schemes.

The implementation of a series of public policies on heritage conservation and development of Lijiang Old Town during the years from 2002 to 2005 which based on the notion of 'living heritage' was the first significant attempt in conservation of this kind of heritage in China, which achieved corresponding effect and prevented Lijiang Old Town from degrading to a complete tourism destination and museum.

However, it is very regrettable that the policy has not been implemented effectively and in the long term. Firstly, the 'subsidy plan' eased due to the withdrawal of GHF, and the Lijiang government did not put a percentage of revenue to the annual restoration budget despite the rapid increase in tourism income. The lack of effective intervention caused serious problems in the restoration of the vernacular buildings and the authenticity has been lost to great extent. Simultaneously, the local residents lost interest to stay in the property area again. Secondly, the business permit mechanism gradually lost intervention effect due to the large scale commercial interests driven as well as the lack of heritage management ability. Therefore, big changes of commerce in the old town happened again since 2006 .

To some extent, with the indigenous people moving out and swarming of migrant population, the Lijiang Old Town once again took economic benefit as the main goal. This has caused the gradual neglect of the social and environmental benefits, leading to social and security problems such as the increasing numbers of fire hazards.

\section{Conclusion}

Now, the latest 'World Heritage Site-Lijiang Old Town Conservation Plan' is undergoing. Fully realising the above problems, the plan emphasises on the establishment of management mechanism, building management, tourism management, capital management, file management, disaster prevention and crisis management, daily monitoring, human resource management, social management, and intangible heritage conservation, etc. It especially emphasises on the tourism capacity control, to avoid excessive development and resource waste, ensure the economic, environmental, social and cultural interests brought by tourism development, seek coordinated development of tourism and heritage, and benefit the future generations. But it is impossible to rely only on this plan to solve the server reality problems, which need common efforts of all aspects to face. Whatever, the common understanding of taking the 'human-inhabited World Heritage' as the 'living heritage' is the base.

Therefore, it must be emphasised that: just as the world heritage city has been built throughout hundreds of years by the people living there, the conservation and development of future heritage site have to rely on the residents living there is redundant and repeated. In the history of the city, it is the attitude of the local people and migrant population that determines the future of the city. We have to change the original concept of physical conservation to the principle of 'integrated conservation': Heritage conservation is an integrated work, so the principle of integrated protection is particularly important towards the historical city which is in special natural and cultural environment. The conservation should not only focus on the artificial physical heritage, but also on the natural and ecological system which is the essential background and environment, the local historical culture and tradition as the origin of the physical heritage, and the local social life system 
forming in history. We advocate especially focusing on the following aspects in this kind of heritage:

1. Historical cultural inheritance of heritage sites

We should fully understand and respect the local history and culture, record and learn the special knowledge system that they have inherited for hundreds of years, and actively create all kinds of possibilities to promote the inheritance and development of the traditional culture. All the people should receive the education about culture and the significance of historical heritage whatever indigenous residents or political leaders. The ultimate aim is to lead to harmony between human and nature, tradition and modern, and the coordinated development of cultural, ecological and economic.

2. Rational utilisation of historical and cultural resources

It is necessary to take a cooperative manner and establish rational rules in cultural and economic feedback in the process of combination of culture and art and economic benefit. The rules will return the benefit to the original culture 'authors' who have taken hundreds of years to create, learn and inherit the resources.

3. Sustained strategy of social life system

It is urgent to strengthen the capacity building of local communities and authorities and to resist external impact as soon as possible under the background of rapidly foreign population swarming in and local residents gradually becoming weak. It is extremely important and urgent to build organisations and activities conducive to the local cultural development, and guarantee adaptive policies and enough funds. Only when residents become the real main subject to construct the local culture through discussion and public participation, the local culture will grow and prosper from the bottom up .

\section{Acknowledgements}

My deepest thanks to the Protection and Management Bureau of the World Heritage Site of Lijiang Old Town and Global Heritage Fund for their generous support.

This work was supported by NSFC (National Natural Science Foundation of China): Study on the Conservation and Utilisation of Human-inhabited World Heritage Resources in China, Project No.: 50978187.

\section{Notes}

1. The data of the Gucheng District are from 2003 since it was set up according to the administration district reformed.

2. Per capita consumption $=$ the domestic tourism income/ the number of domestic tourists. And the statistics of nation is lack before 1993 .

3. According to the administration district currently, the population of Dayan Old Town mainly concentrates in 6 communities: Xinhua, Xinyi, Guangyi, Wuyi, Qiyi and Yishang community.

4. Since 2004, in order to encourage the indigenous residents to live in the property area, Lijiang Municipality provides a subsidy for the residents in the Old Town of 15 CNY per person per month. The paper defines this kind of people as 'benefited residents' which reflects the ratio of remaining indigenous residents in the property area.

5. Migrant population in China are commonly members of a floating population, which refers primarily to migrants without local household registration status through the Chinese Household system, not including the tourists.

6. In 2005, the Protection and Management Bureau of the World Heritage Site of Lijiang Old Town was established based on this office.

\section{References}

Edroma, L. Eric. 2003. "Linking Universal and Local Values for the Sustainable Management of World Heritage Sites" In Linking Universal and Local Values: Managing a Sustainable Future for World Heritage, edited by Eléonore de Merode, Rieks Smeets and Carol Westrik, 36-42. Paris: UNESCO World Heritage Centre.

Engelhardt, A. Richard, and Pamela R. Rogers. 2009. Hoi An Protocols for Best Conservation Practice in Asia: Professional Guidelines for Assuring and Preserving the Authenticity of Heritage Sites in the Context of the Cultures of Asia. Thailand: UNESCO Bangkok, Asia and Pacific Regional Bureau for Education.

Fan, Tao. 2008. "Research on the Evolution Process and Trend of Eco-geological Environment of Lijiang, Northwest of Yunnan.” PhD diss., Kunming University of Science.

Global Heritage Fund (GHF). 2008. Lijiang Ancient Town-UNESCO World Heritage Site: Master Planning and Historic Preservation (2003-2007). GHF Technical Assessment.

He, Shiyong. 2011. World Cultural Heritage Lijiang Old Town Chronicle. Kunming: Yunnan Nationalities Press.

Huang, Yu, Tianxin Zhang, and Takayoshi Yamamura. 2009. "Research on the Relations Between Tourism Business Population and Spatial Distribution of Lijiang Old Town." Chinese Gardens 25 (5): 23-26. 
ICOMOS. 2009. World Heritage in Danger: A Compendium of Key Decisions on the Conservation of Cultural Heritage Properties on the UNESCO List of World Heritage in Danger (Compendium II).

ICOMOS. 1999. International Cultural Tourism Charter: Principles and Guidelines on Important Cultural Monuments and Sites Tourism Management. Mexico.

Jiang, Gaochen. 1997. Lijiang: Beautiful Naxi Homeland. Beijing: China Building Industry Press

Rock, Joseph. 1999. The Ancient Naxi Kingdom of Southwest China. Translated by Zongyue Liu. Edited by Xuan Ke. Kunming: Yunnan Fine Arts Press

Li, Hui. 2004. "Lijiang Yulong Snow Mountain is in Danger”. Ecological Economy (7): 75.

Lijiang Old Town District Statistics Bureau. 2005-2012. "National Economy and Society Developed Statistical Bulletin (2004-2011)". Accessed June 1 2017. Yunnan Government. http://ynxxgk.yn.gov.cn/M1/Index. aspx?int_DepartmentID $=1$

Li, Jie. 2007. Develop Evolution of Lijiang Naxi Culture. Beijing: Minzu University of China Press.

Ministry of Construction of the People's Republic of China. 1997. World Cultural Heritage: Lijiang Old Town. China. Shanghai

Shanghai Tongji Urban Planning \& Design Institute. 2007. "World Cultural Heritage Lijiang Old Town Conservation Plan". Shanghai

Shao, Yong. 2012. "Heritage Conservation and Social Development: Case of World Cultural Heritage Lijiang Old Town Conservation Policy." Paper presented at the $7^{\text {th }}$ Urban Development and Planning Conference, Guilin, June 12-13.

UNESCO. 1972. Convention Concerning the Protection of the World Cultural and Natural Heritage. Paris

Yamamura, Takayoshi, Tianxin Zhang and Tengmu Yongjie. 2007. Revitalization of World Heritage Site: Lijiang, Yunnan Province, China. Kyoto: World Thought Press.

Yang, Fuquan. 2006. Naxi Ethnic Cultural History. Kunming: Yunnan University Press.

Yang, Fuquan, and Yuxiang Li. 2005. "Lijiang, Stick Together with Mountains and Waters in Life and Death." Chinese Heritage (6): 46-52.

Yang, Fuquan. 2005. “The Mutual Influence and Integration between Naxi Culture and Han Culture in the Old Town of Lijiang". Ideological Front 31(2): 48-53.

Yang, Fuquan. 2008. "A Preliminary Study of the Eco-ethics of the Naxi Nationality." Journal of Yunnan Nationalities University (Philosophy and the Social Sciences
Edition) 25(1): 38-42.

Yang, Fuquan. 2010. “The Influence of Socio-cultural Changes on the Ethnic Religious Identification: The Naxi's Identification with Dongba Religion and its Changes." Thinking 36(4): 15-20.

Yang, Guifang, Ding Wenjie, and Ge Shaode. 2005. World Cultural Heritage: Research on Lijiang Old Town Tourism Environment. Beijing: Nationalities Press.

Yang, Hongjie. 2010. "Lijiang Old Town: The dilemma under the Great Reputation”. China Culture Daily.

Yu, Hong. 2007. "Lijiang Old Town Formation Development and Naxi National Culture Evolution”. PhD diss., Minzu University of China. 